\title{
Electrical Conductivity Structure in the South-east Australian Region
}

\author{
D. J. Bennett* and F. E. M. Lilley
}

(Received 1973 August 27)

\begin{abstract}
Summary
An array of variometers across south-east Australia has recorded natural magnetic variations having power in a frequency band of $0 \cdot 04-10$ cycles $/ \mathrm{hr}$. The set data have outlined two major regions of high terrestrial electrical conductivity $(\sigma)$; the first beneath the sea floor off the Australian southeast coast; the second in the vicinity of the most recent eruptive centres of the 'Newer Volcanics' in western Victoria. Both regions may indicate low $Q$ upper mantle zones. Daily variation data provide significant control on permissible conductivity models.
\end{abstract}

\section{Introduction}

Previous studies of natural magnetic variations in Australia (Parkinson 1959; Everett \& Hyndman 1967; Bennett \& Lilley 1971) indicate large 'coast effect' anomalies at various points near the edge of the continent. These anomalies are important since, besides the effect due to conductive ocean waters, they could also be due in part to contrasts between ocean and continent of conductivity structure in crust and upper mantle.

The present study utilized 26 magnetic variometers across an area stretching inland from the coastlines of south-east Australia (Fig. 1). The extensive area covered facilitates a separation of the 'coast effect' in this region from other local induction anomalies, and from effects due to spatial non-uniformity of the primary variation field.

Several earlier papers have presented analyses of magnetic sub-storm data (Lilley \& Bennett 1972) of micropulsation data (Lilley \& Bennett 1973a) and of magnetic daily variation data (Bennett \& Lilley 1973); covering in all a frequency band of about 0.04-10 cycles/hr. The present paper synthesizes these observations into an interpretation of the major electrical conductivity structures of the region's crust and upper mantle. A full account of the study, including a complete folio of the frequency contour maps and Parkinson vector plots used in quantitative interpretation, is given by Bennett (1972) in a thesis presented at the Australian National University.

\section{Major variation structures}

The various contour maps presented in the aforementioned papers reveal that south-east Australia is a zone of very complex magnetic variations' structure. This is certainly due to strongly three-dimensional conductivity configurations in the Earth;

- Now at University of Texas at Dallas, Box 30365, Dallas, Texas 75230. 

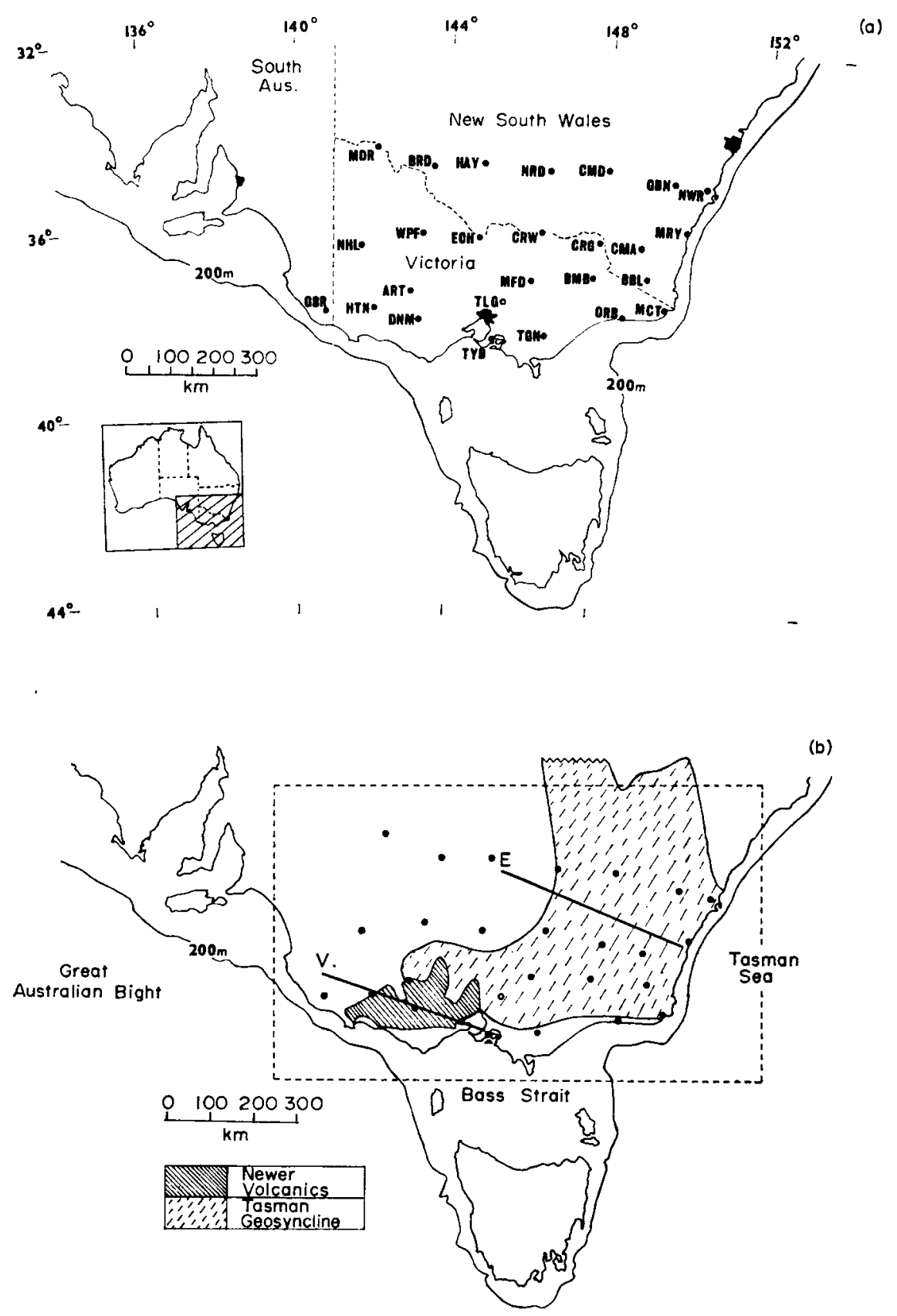

(b)

FIo. 1. (a) Map of observing sites with code names. (b) Major tectonic features in the array area. Modelling profile lines $\mathrm{V}$ and $\mathrm{E}$. The dashed rectangle forms the frames in Fig. 2.

as witness initially the presence of highly conductive deep oceans on two sides of the array.

By using the polarization of the horizontal variation field as an aid in separating the various contributions to the anomalous vertical $(Z)$ variation field (Bennett \& Lilley 1972), several distinct variation features can be described. 


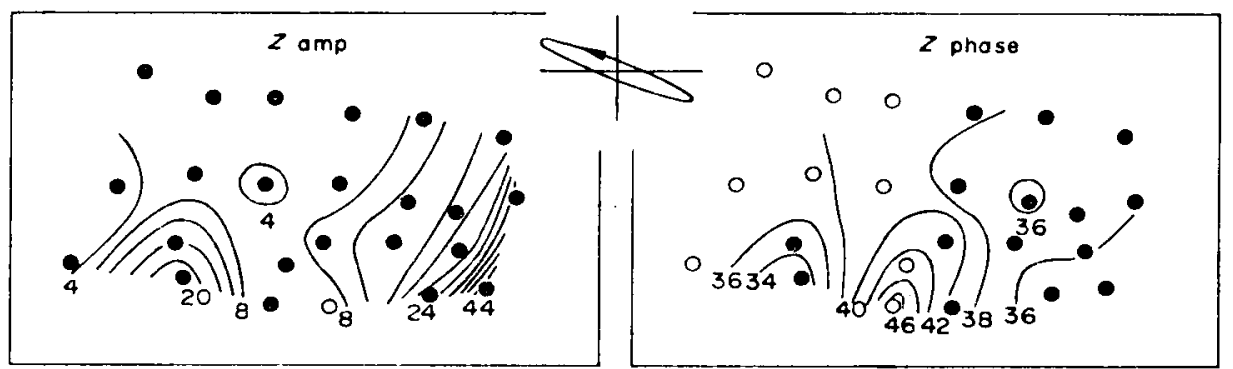

FIG. 2. Vertical $(Z)$ Fourier transform parameter maps for 1971 April 11, 1500$1800 \mathrm{GMT}$; at a period $46 \mathrm{~min}$, with ellipse of horizontal polarization. Units of phase are minutes; units of amplitude are $9 \mathrm{nT} /$ cycle $/ \mathrm{min}$.

The major feature is a large 'coast effect' (the East Coast Anomaly) especially of the vertical $(Z)$ field, along the New South Wales coast. In another region, southwest Victoria, complicated anomalous $Z$ responses are apparently composed of a coast effect associated with the adjacent Great Australian Bight coastline, and a second contribution due to some other local excess of induced current flow (the Victorian Anomaly). Amplitude highs of the horizontal field are also often observed in the region north of the Bass Strait.

Bennett (1972) includes a detailed morphology of these features; however, the present paper is limited to a discussion of the East Coast Anomaly (qv) and the Victorian Anomaly (qv). Both these features are clearly shown on the $Z$ amplitude contour map of Fig. 2 (note the polarization ellipse of the corresponding horizontal field: this results in accentuation of both these anomalies).

\section{The East Coast Anomaly}

\section{Inductive mechanism}

This anomalous feature is quite typical of the 'coast effect' anomalies observed in various parts of the world (Hyndman \& Cochrane 1972, review). It has a near twodimensional form (Fig. 2), with $Z$ amplitude contour lines closely parallel to the very linear New South Wales coast. This implies that an excess of induced current is flowing parallel to the coastline on the ocean side of the conductivity interface; giving anomalous vertical variations near the coastline.

Bullard \& Parker (1970) have considered electric current induction on a global scale in the oceans by primary $Z$ variations as being the most important mechanism in producing such 'coast effect' anomalies. However, should large lateral $\sigma$ contrasts in the crust or mantle occur near ocean edges, then local induction through the horizontal variation component perpendicular to the strike of the contrast could be an alternative major cause of a 'coast effect' anomaly. A vital first stage in interpretation is to consider the relative importance of these two inductive processes in producing the East Coast Anomaly.

For most ' coast effect ' anomalies, including the Australian East Coast Anomaly, a 'Parkinson vector' relationship has commonly been observed at periods less than about two hours. This relationship takes the form of a stationary linear dependence of the (complex) $Z$ amplitude on the (complex) amplitude of the horizontal variation component $Y^{\prime}$ perpendicular to the ocean edge. Lilley \& Bennett (1973b) have argued on theoretical grounds that induction by the vertical $(Z)$ field to give a Parkinson vector relationship requires large anomalous horizontal fields to be associated with anomalous $Z$. This is in contradiction to the character of the East Coast Anomaly, as 
observed in the magnetic substorm and micropulsation data; where the horizontal component $Y^{\prime}$ varies in amplitude by no more than 10 per cent over a range extending several hundred kilometres inland from the coastline. In contrast, the $Z$ field can vary by several 100 per cent over the same range.

Further following Lilley \& Bennett (1973b) and also Hyndman \& Cochrane (1972), it is here assumed that the Parkinson vector relationship observed in the micropulsation and magnetic substorm data is predominantly due to induction by a horizontal variation component $Y^{\prime}$ roughly perpendicular to the coastline. Moreover, the consistent stationary nature of this relationship, irrespective of the changing spatial configurations of different source events, further implies that most anomalous current is induced in some region localized around the coastline, rather than on a global scale.

The foregoing conclusions are not so easily drawn for the daily variations' data; where a large 'normal' $Z$ maintains a closely repeatable day-to-day relationship with the horizontal variation components. However, Bennett \& Lilley (1973) have shown that here too the most consistent explanation for the large anomalous $Z$ observed near the Australian east coast is in terms of induction through horizontal component $Y^{\prime}$ roughly perpendicular to the coastline. It is therefore assumed that modelling of the East Coast Anomaly over the whole frequency band is best approximated by the effect of horizontal induction in a two-dimensional conductivity structure, which represents an average vertical section of terrestrial conductivity in the plane perpendicular to the coastline. The two-dimensional approximation is justified at present by noting the extended linear form of the observed anomalous $Z$ amplitude contours parallel to this coastline, implying extended linear current flow.

For such two-dimensional cases, Maxwell's equations reduce to two independent sets of relations (Jones \& Price 1970). The $E$-polarization case for a uniform source field with current flowing in the horizontal $x$-direction for symmetry through the $y-z$ plane, is most relevant to the case of anomalous $Z$ related to mostly 'normal' local $Y^{\prime}$. A standard computer formulation of the uniform source field $E$-polarization case, due to Jones \& Pascoe (1971) and Pascoe \& Jones (1972), appropriately adapted for present requirements, was used to model the Australian East Coast Anomaly. The modelling inaccuracy introduced by the uniform source field approximation is not considered too severe, since typical spatial wavelengths of variation events appear to be much greater than the scale of lateral conductivity structure.

\section{Modelling procedure}

In the procedure followed, lateral variations in conductivity were modelled as relative perturbations at appropriate depths of a horizontally-stratified ' normal' conductivity profile, taken to represent the average radially-dependent absolute conductivity of the region. No attempt was made to determine this absolute profile by the 'normal field' approach, such as in Gough \& Camfield (1974), principally because of the difficulty in estimating spatial wavelengths and 'normal' $Z$ parameters from the frequency contour maps. The magneto-telluric results of Tammemagi \& Lilley (1971) over the Tasman Geosyncline (Fig. 1) and the rise of conductivity to a value of about 1 (ohm-m) ${ }^{-1}$ at about $400 \mathrm{~km}$ depth, as estimated from long period global depth sounding by Banks (1969) and Parker (1970), were used as shallow and deep controls respectively, on a normal conductivity profile. The conductivity at intermediate depths was formed by combining laboratory estimates of olivine conductivity (e.g. Duba \& Nicholls 1973) with an appropriate global geotherm (Bennett 1972). The resulting normal conductivity profile is shown in Fig. 3. The Tasman Sea was represented as a conductor with $\sigma$ of $4(\mathrm{ohm}-\mathrm{m})^{-1}$ and thickness $4 \mathrm{~km}$.

In order to utilize the whole frequency band of observations, whilst keeping the curve fitting procedure within manageable proportions, two simple modelling parameters were adopted. The more important parameter was obtained from the $Z$ amplitudes. The $Z$ variation field was divided, after the manner of Schmucker (1970), 


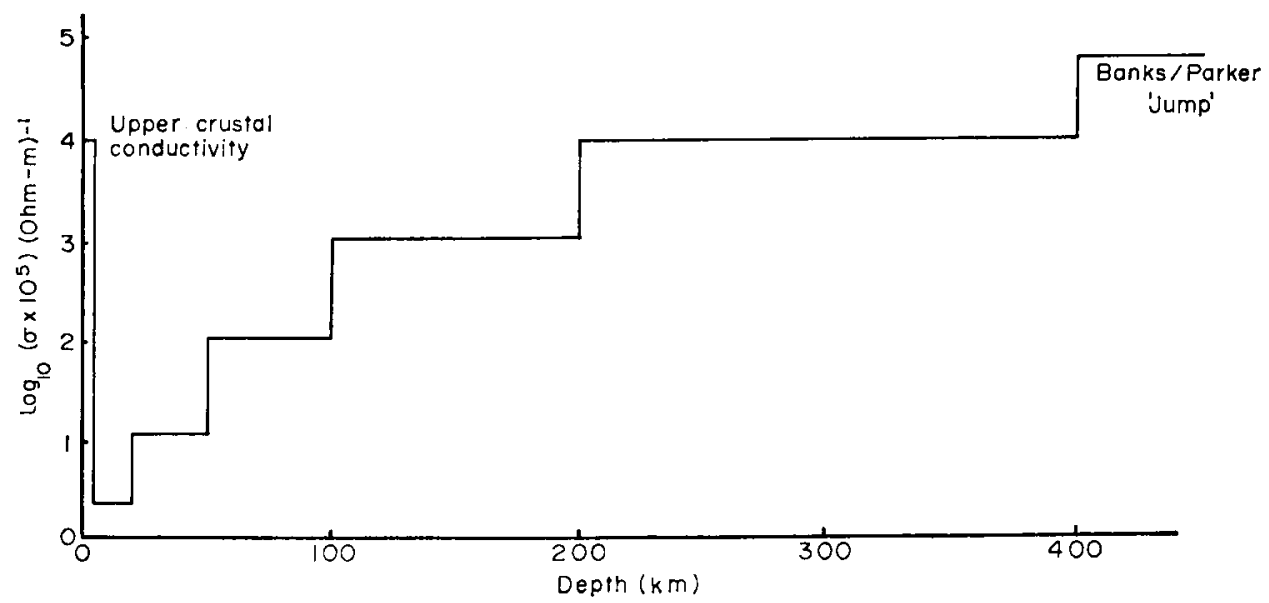

FIG. 3. Constructed 'normal profile' of electrical conductivity against depth. Units of conductivity are $\log _{10}\left(\sigma \times 10^{5}\right)(\mathrm{ohm}-\mathrm{m})^{-1}$.
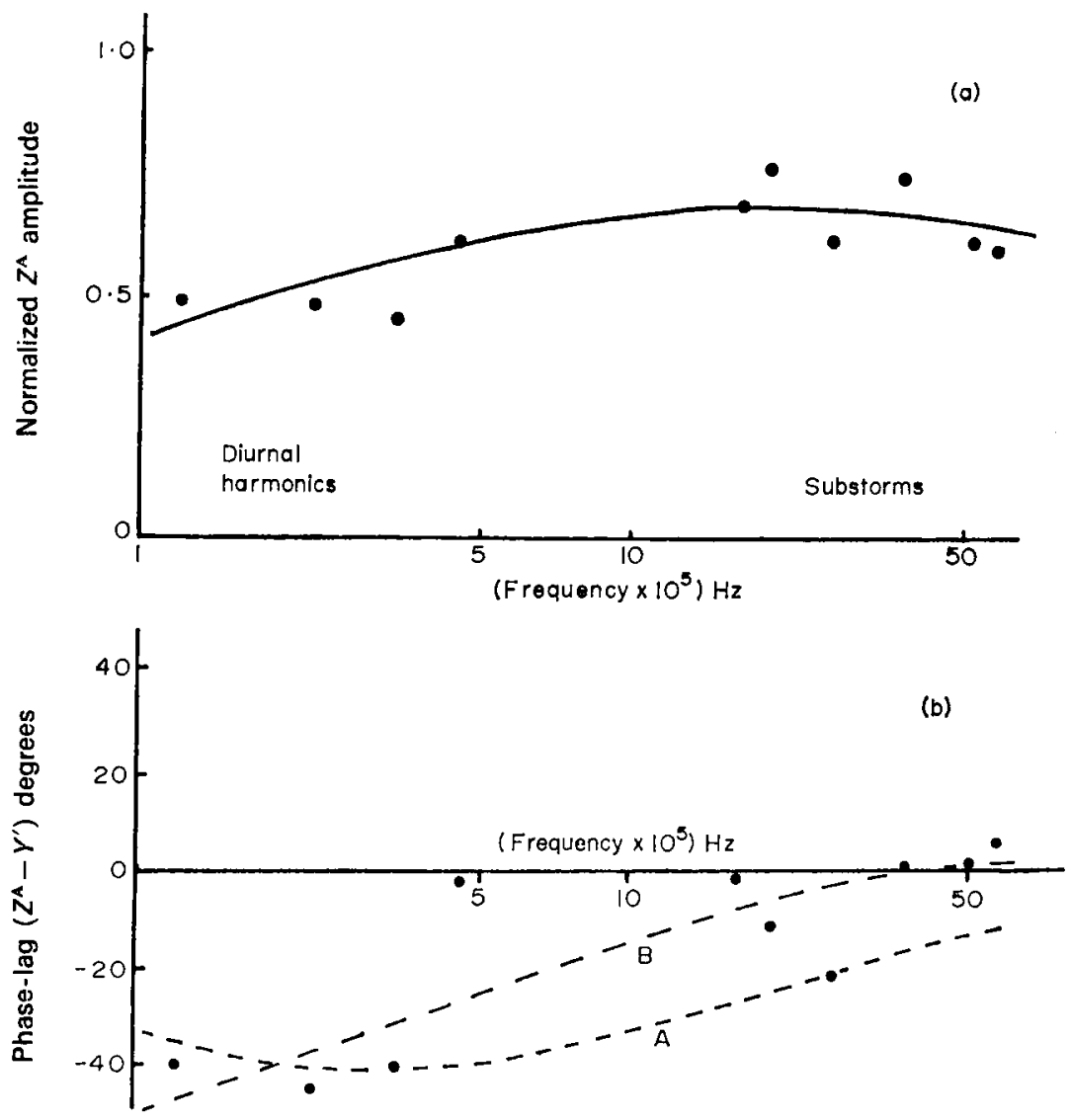

FIG. 4. (a) Values of $Z^{A}$ amplitude $v$. frequency response at station MRY. $Z^{\wedge}$ amplitude normalized as per text. The solid line is a least squares quadratic fit to the points. (b) Values of $\left(Z^{A}-Y^{\prime}\right)$ phase $v$. frequency response at station MRY. Phases are lags, in degrees. The dashed lines are theoretical phase $v$. frequency responses for ocean waters with ' normal profile ' (curve A); and for ocean waters + sub-oceanic conductive zone similar to Fig. 7, with 'normal profile' (curve B). 
into an 'anomalous' component $Z^{\mathrm{A}}$, related to the lateral conductivity contrasts at the coastline; and a 'normal' component $Z^{\mathrm{N}}$, which is a function of the average horizontally stratified conductivity structure of the region. The $Z^{\mathbf{N}}$ is also a function of spatial wavelength (being zero for infinite spatial wavelength), and is quite poorly determined. For all frequencies studied except those of the diurnal harmonics, $Z^{\mathrm{N}} \ll Z_{\max }^{\mathrm{A}}$ and an estimate of $Z^{\mathrm{N}}$ was arbitrarily assumed as 50 per cent of $Z$ at a western point on profile line $E$ (Fig. 1) $400 \mathrm{~km}$ from the continental edge of eastern Australia, since at such a point $Z=Z^{\mathrm{N}}+k Z_{\max }^{\mathrm{A}}$ where $k \ll 1$. The errors introduced in this approximation are small compared to $Z_{\max }^{\mathrm{A}}$. At the diurnal harmonics, $Z^{\mathrm{N}}$ and $Z^{A}$ were comparable in magnitude, and were separated by construction of a $Z^{\mathbf{N}}$ field based on a global analysis of $S q$ (Bennett \& Lilley 1973). The $Z$ at the coastal station MRY was taken as being well controlled and most representative of the maximum observed anomalous effect of the postulated two-dimensional conductivity structure across the ocean-continent boundary. The station MRY is at the eastern end of profile line $E$ and some $50 \mathrm{~km}$ from the continental edge.

The normalized modelling parameter $Z^{\mathrm{A}}=\left(Z_{\mathrm{MRY}}-Z^{\mathrm{N}}\right) / Y^{\prime}{ }_{\mathrm{MRY}}$ was formed at a number of frequencies (Fig. 4(a)). This was compared with the parameter $Z_{\text {model }}^{\mathrm{A}}=$ $\left(Z_{50}-Z_{400}\right) / Y^{\prime}$ s0 $_{\text {model }}$, formed from calculated values of $Z$ and $Y^{\prime}$ at $50 \mathrm{~km}$ and $400 \mathrm{~km}$ from the model 'ocean edge'. Because of the very large conductance of the oceans, practically all physically reasonable models show an anomalous $Z$ which peaks in the vicinity of the ocean edge and decays sharply on the continental side. This could produce a large systematic error in the comparison of model curves with Fig. 4(a), due to the uncertainty in locating the effective conductivity boundary of the deep ocean water near the Australian continental edge. Bennett (1972) has shown that such an error, whilst systematically raising or lowering the absolute amplitudes of the $Z_{\text {model }}^{\mathrm{A}} v$. frequency curve, does not appreciably alter the shape of $\operatorname{such} Z^{\mathrm{A}}$ curves. Thus the fitting by eye of model curves to Fig. 4(a) is based first on the shape of $Z^{A} v$. frequency; with a latitude of some \pm 0.05 in fitting the level of absolute amplitude of this normalized $Z^{\mathrm{A}}$, corresponding to an 'ocean edge' uncertainty of about $10 \mathrm{~km}$.

The $Z$ phase near the east coast is not considered a good modelling parameter. This is partly because the phase errors introduced in the separation of $Z^{\mathrm{A}}$ and $Z^{\mathrm{N}}$ for the diurnal harmonics are not well determined; but more importantly, because significantly different conductivity models do not produce very different $Z$-phase responses. In general, model $Z$-phase responses agree well with the observed phase difference of $Z$ and $Y^{\prime}$ across the whole frequency band, as shown in Fig. 4(b).

The second modelling constraint is that the amplitude of the horizontal $Y^{\prime}$ field near the east coast does not exceed that of $Y^{\prime}$ several hundred kilometres west of the coast by more than about 10 per cent, over the whole frequency range. This constraint is useful in separating models which satisfy the stronger $Z$ amplitude constraint equally well.

\section{Modelling results}

The first class of models examined was that where the semi-infinite ocean-water 'sheet' provided the only lateral conductivity contrast. Typical model $Z^{\mathbf{A}}$ frequency curves of this type are shown in Fig. 5. Sensitivity of $Z$ response to differing conductances of the background normal profile was easily tested by expanding (curve $A$ ) or contracting (curve D) the vertical scale of the normal profile shown in Fig. 3. The effect of removing the surface conducting layer of the normal profile was also tested (curve B). No reasonable fits could be obtained, and it was therefore concluded that large scale differences of conductivity do exist between the continental and the suboceanic crust and mantle of this region. Note that this important conclusion comes mainly from the low frequency data provided by analysis of the diurnal harmonics, and also that it is not dependent on the assumed normal profile. 


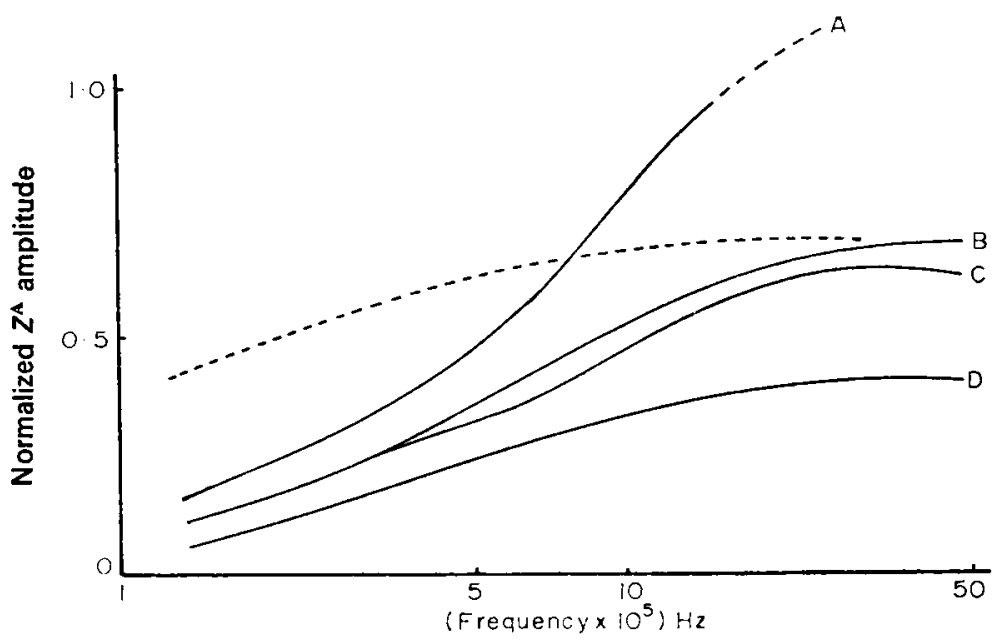

FIG. 5. Theoretical $Z^{\mathrm{A}}$ amplitude $v$. frequency responses, normalized as per text, at a position $50 \mathrm{~km}$ landwards of ocean edge. Underlying horizontally stratified conductivity layering is the normal profile with vertical scale $\times 2$ (curve A); normal profile without surface conducting layer (curve B); normal profile of Fig. 3 (curve C); and normal profile with vertical scale $\div 2$ (curve D). The curve of Fig. 4(a) is shown as a dashed line.

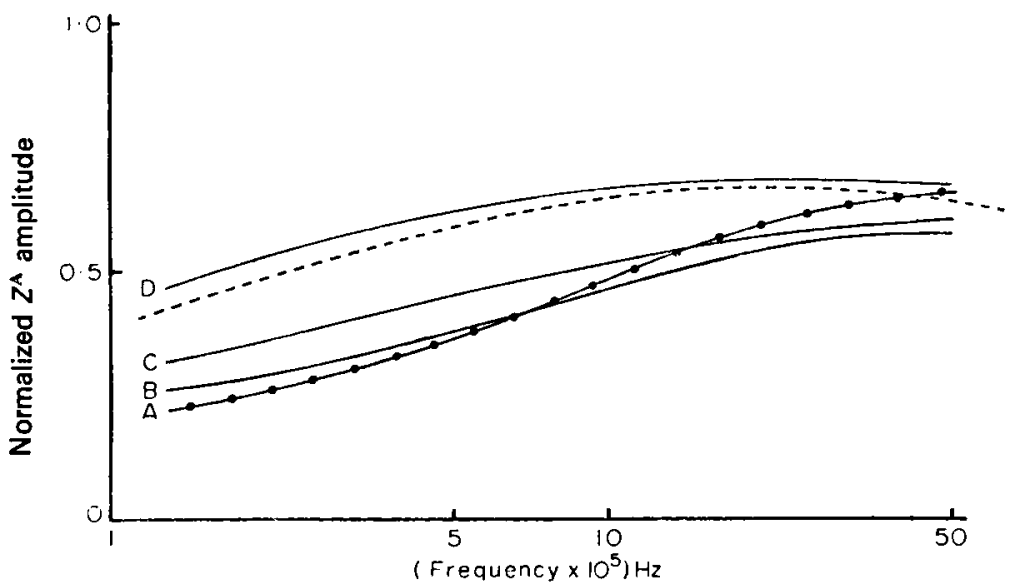

FIG. 6. Theoretical $Z^{A}$ amplitude $v$. frequency responses, normalized as per text, at a position $50 \mathrm{~km}$ landwards of ocean edge. Underlying conductivity structure is normal profile + sub-oceanic zone of conductivity 1 (ohm-m) ${ }^{-1}$ and thickness $100 \mathrm{~km}$ at depth to upper surface of $100 \mathrm{~km}$ (curve A), $75 \mathrm{~km}$ (curve B), $50 \mathrm{~km}$ (curve C), and $10 \mathrm{~km}$ (curve D). The curve of Fig. 4(a) is shown as a dashed line.

Further modelling was devoted to outlining the range of possible conductivity configurations which reasonably satisfy the constraints. Fig. 6 shows the change in $Z$ response as a zone about $100 \mathrm{~km}$ thick, of conductivity $1(\mathrm{ohm}-\mathrm{m})^{-1}$, situated only below the ocean, is moved upwards from a depth of $100 \mathrm{~km}$ to a depth of $10 \mathrm{~km}$. An approach to a suitable fit of the $Z$ amplitude parameter is apparent. The $Y^{\prime}$ amplitude constraint now becomes important in defining the position of the edge of the conductive zone underneath the ocean edge. More extensive details of the various classes of models considered are given in Bennett (1972). 


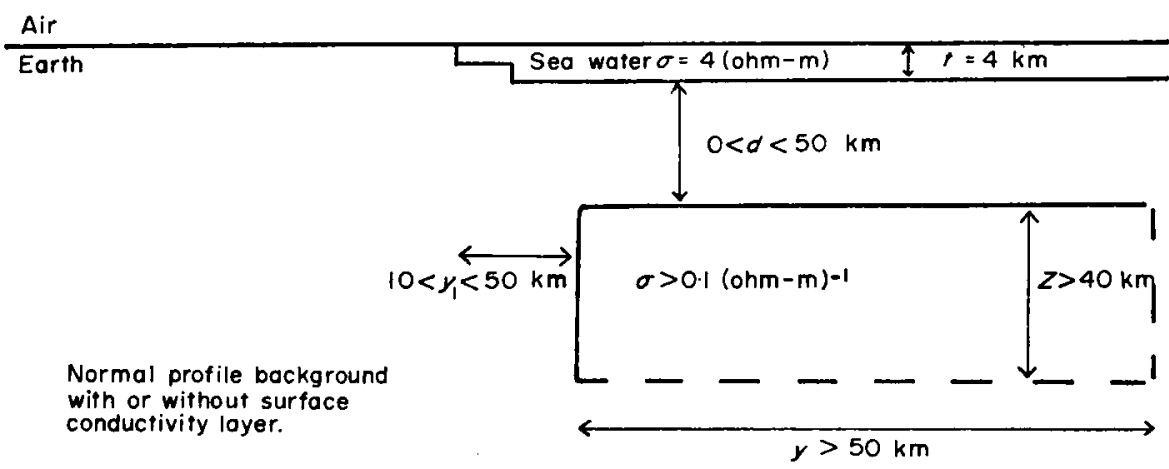

Fig. 7. Schematic section of the postulated conductivity structure beneath the western Tasman Sea and eastern New South Wales.

Estimates of the parameters of the required conductive zone beneath the ocean are shown in Fig. 7. The intricate balance between the various parameters, such as conductivity, depth and thickness of the conductive zone, is difficult to establish on the basis of the limited number of models generated, and the final model is of necessity rather conceptual in outline.

Note:

(1) The $Y^{\prime}$ amplitude constraint requires either that the edge of the zone be displaced seawards (as shown), or that the top edge of the zone be tapered upwards in a seawards direction. Either approach allows the magnetic field lines to deviate more smoothly across the conductivity boundary, thus reducing $Y^{\prime}$ at the ocean edge whilst not changing the character of the $Z v$. frequency curve.

(2) The minimum depth parameter is closely linked to the anomalous conductivity; and the depth range shown was estimated for a physically reasonable upper limit on conductivity of $1(\mathrm{ohm}-\mathrm{m})^{-1}$, (which could, for instance, be appropriate to molten basalt above $1200^{\circ} \mathrm{C}$ ). Raising the conductivity another order of magnitude could increase the minimum depth by up to a few tens of kilometres.

(3) The minimum thickness parameter was estimated for an anomalous conductivity of $1(\mathrm{ohm}-\mathrm{m})^{-1}$, whilst the minimum conductivity of $0.1(\mathrm{ohm}-\mathrm{m})^{-1}$ is a necessity of producing any observable anomalous $Z$ effect above that due to the large conductance of the ocean waters. Thus these two parameters should not be combined to give a minimum conductance for the zone.

(4) The results are obviously linked to the normal profile 'background' of Fig. 3, used in modelling. Increasing the conductance of the background necessitates increasing the parameters of the anomalous conductive zone, both to maintain the necessary lateral conductivity contrasts and to overcome the increased electromagnetic damping of the downwards diffusing inducing field. The converse is, of course, also true (cf. Fig. 5).

In conclusion, a zone of anomalously high conductivity as compared to the continental normal profile is considered to exist beneath the western Tasman Sea off the New South Wales east coast. The outline of this zone shown in Fig. 7 must be regarded only as a rough guide, since observations have been made only of that part of the anomaly occurring over the continent; and interpretation is very dependent on the effect observed in the long period diurnal harmonics. 


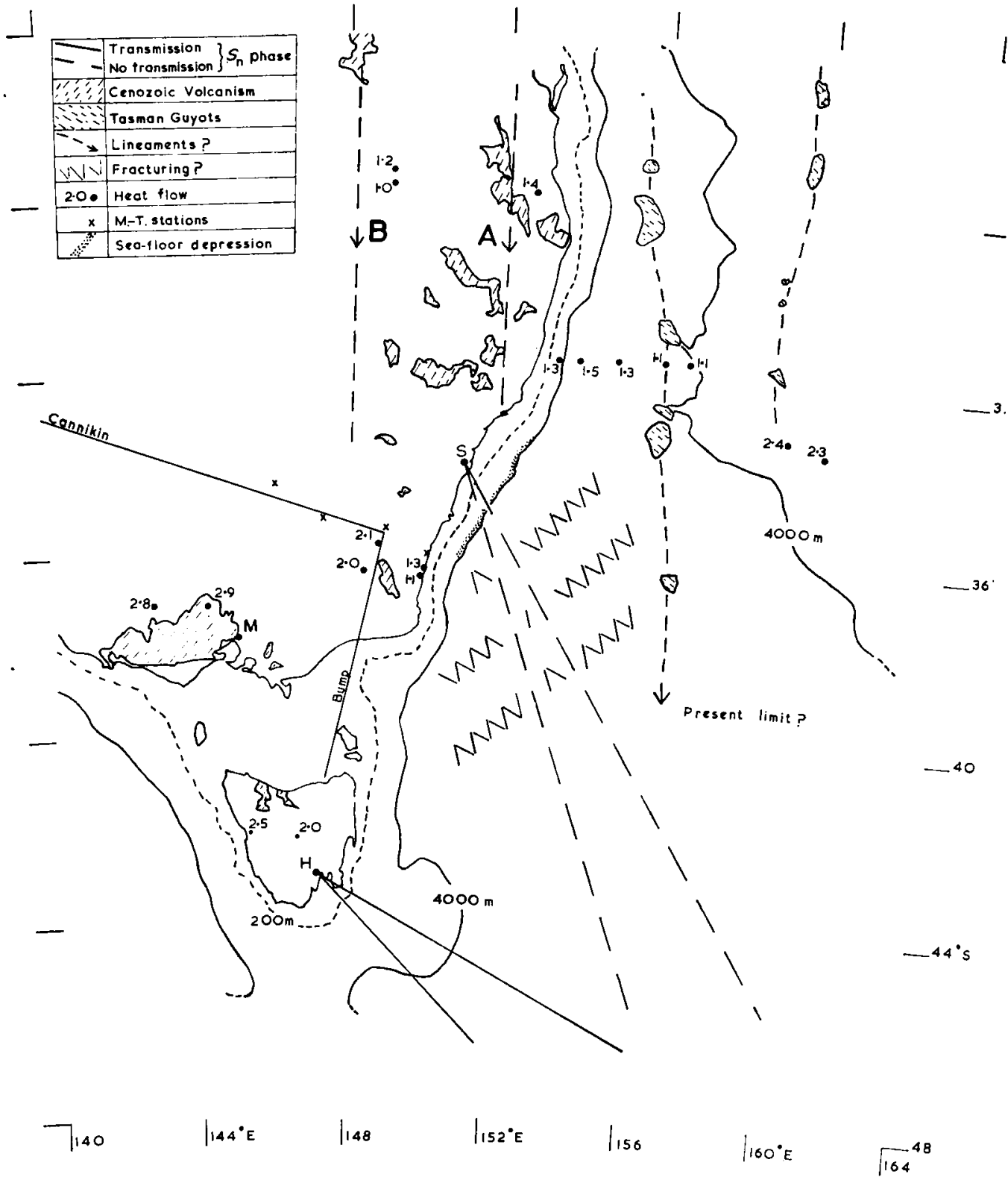

FIG. 8. Various tectonic and geophysical features of eastern Australia and the western Tasman Sea. Also marked are Sydney (S), Melbourne (M) and Hobart (H). Sources quoted in text.

Observations of any of the electromagnetic elements made on the ocean side of the coastline should greatly clarify this result, as should better determinations of the continental normal profile.

\section{Geological interpretation}

The approximate dimensions of the postulated sub-oceanic conductive zone shown in Fig. 7 preclude the possibility that it represents high conductivity in the 
oceanic crust. Major possibilities for anomalously high conductivity in the oceanic upper mantle may be:

(1) Mineral conduction in hydrothermally altered fractions of the lithosphere (Cox 1971).

(2) The presence of ferric iron in the upper mantle (Duba 1972; Duba, Ito \& Jamieson 1973; Duba \& Nicholls 1973).

(3) Continuous partial melt (Presnall, Simmons \& Porath 1972) due to the intersection of geotherm and solidus of the local mineral assemblage. An elevated oceanic geotherm also implies increased intrinsic conductivity of the solid phase, but by itself would appear unlikely to produce the apparently fairly abrupt lateral conductivity change.

Although all the above mechanisms may have a contribution, it is thought that the partial melt zone best satisfies the minimum dimensions of the postulated conductive zone (Fig. 7) and the requirement that it form a lateral conductivity contrast with the sub-continental conductivity profiles. (Assuming the conductivity of the partial melt could approach that of molten basalt above $1200^{\circ} \mathrm{C}$, the bulk conductivity could rise to values of order 1 (ohm-m) $)^{-1}$ (Duba \& Lilley 1972). This is an interesting possibility from a tectonic viewpoint, since under stable oceanic basins, surface wave dispersion data (Brune 1969; Kanamori \& Press 1970) and oceanic heat flow (Sclater \& Francheteau 1970; Sclater 1972) suggest low- $Q$ partial melt zones may not lie at depths shallower than about $60 \mathrm{~km}$.)

Relevant geophysical data neither strongly supports nor disbars this possibility. Fig. 8 indicates the Cenozoic Tasman guyot chains (Vogt \& Conolly 1971); the rather variable heat flow values in the Tasman (Grim 1969) and on the nearby Australian continent (Hyndman, Jaeger \& Sass 1969) and the region where magnetic mapping (Ringis 1970; Hayes \& Ringis 1972) has indicated sea-floor spreading and transform faulting of the Tasman floor. Furthermore, $S_{\mathrm{N}}$ seismic shear wave phase propagates well from earthquakes on the Macquarie Rise to Hobart, but does not propagate at all along the slightly longer path to Sydney (Molnar \& Oliver 1969), suggesting anomalously low- $Q$ uppermost mantle somewhere along the Macquarie Rise to Sydney ray path north of about latitude $44^{\circ} \mathrm{S}$ (Fig. 8). Bennett (1972) suggests that an anomalously shallow zone of partial melt beneath the Tasman could be consistent both with these and other data, and with current theories on evolution of the Tasman Sea. However more information is clearly required in such fields as oceanic gravity, heat flow and seismic refraction, before a sub-Tasman partial melt zone can be strongly advanced as a cause of the East Coast Anomaly.

\section{Analogy with the Californian Pacific Region}

The similarity of the 'signature' of diurnal harmonic $\left(Z, Y^{\prime}\right)$ relationships for the Australian south-east coast and as observed by Schmucker (1970) for California (Bennett \& Lilley 1973) may establish a link between the electrical conductivity structure of the two regions. Separate magneto-telluric observations on the sea floor adjacent to the California coastline (Cox, Filloux \& Larsen 1970) have been interpreted as showing conductivities as high as $0.4(\mathrm{ohm}-\mathrm{m})^{-1}$ within $30 \mathrm{~km}$ of the surface, as compared to a much lower Californian continental conductivity structure. The general similarity of this interpretation with Fig. 7 for the East Coast Anomaly is clear. It is an encouraging result that having established a comparability link between the two regions through a magnetic variation 'signature', similar interpretations in terms of electrical conductivity structure should then result from two different types of study. 


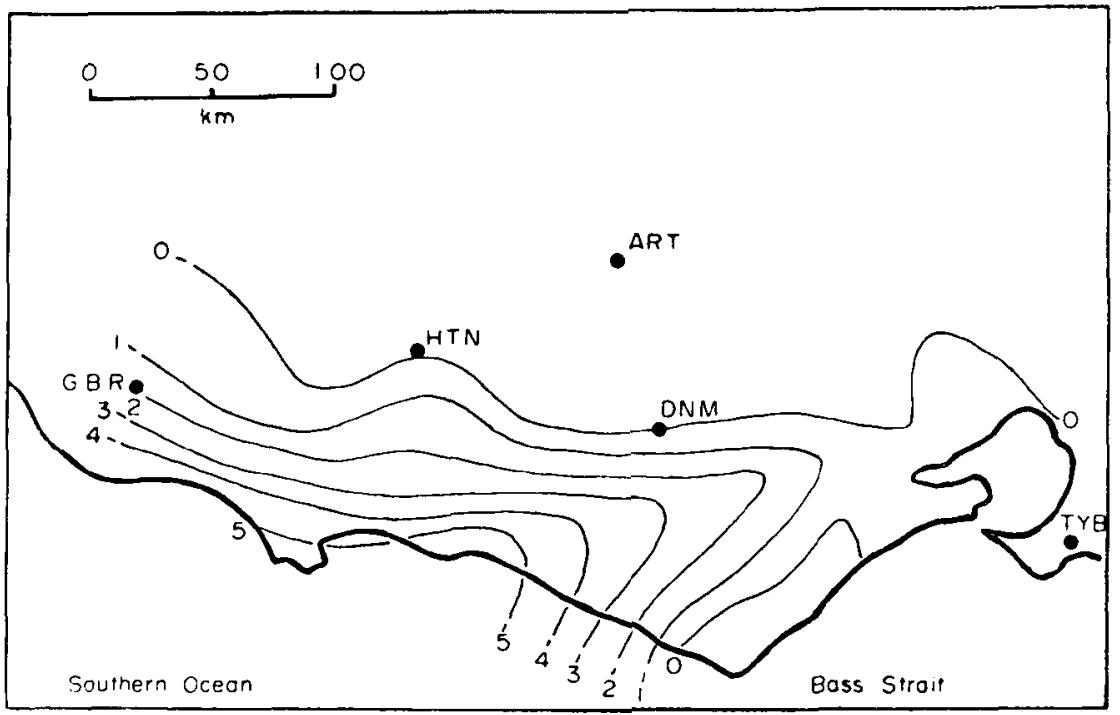

FIG. 9. Estimated depths to basement (in thousands of feet) of Tertiary sediments of Otway Basin, after Ollier (1967). Array study stations marked as dots. Outcrop of Newer Volcanics not marked.

\section{The Victorian Anomaly}

\section{Introduction}

The complexity of the magnetic variations structure in south-west Victoria, west of Melbourne, must be related to the laterally variable conductivity structure of the Earth in this region (Fig. 9). To the south-west of the region lie the deep waters of the Southern Ocean. To the south and south-east are the shallower waters of the Bass Strait, which form a conducting link from the Southern Ocean across to the deep waters of the Tasman Sea. Thick and possibly highly conductive sediments underlie the Bass Strait, increasing the effective conductance of the channel. Between the sea waters to the south and the Newer Volcanics to the north of the anomalous region (Fig. 1(b)), and underlying both ocean and volcanics to some extent, are the thick sediments of the Otway Basin. These sediments are undoubtedly well coupled electrically to the sea waters, and further conductivity structure may well exist in the deep crust and upper mantle of the region. Both local induction and local channelling of remotely induced currents must be considered as possible causes of anomalous magnetic variations.

\section{General morphology of anomalous variations}

A consistent variation pattern for the region emerges on examining frequency contour maps with different horizontal polarizations. For all near-linear substorm polarizations in a roughly NE-SW azimuth, perpendicular to the south-west Victorian coastline, there is a 'coast effect' anomalous $Z$. For all near linear substorm polarizations, with major axes in a roughly NW-SE azimuth, the 'coast effect' becomes small; yet quite consistently, large $Z$ responses (the Victorian Anomaly) appear at stations DNM, ART and HTN (Fig. 1(a) and Fig. 2).

The features of the Victorian Anomaly are summarized from Bennett (1972) as:

(1) Large amplitudes centred near DNM, which are near symmetrical about 
some NNE axis, for all horizontal fields along near WNW azimuths. Sensitivity to fields polarized in the $\mathrm{N}$ to $\mathrm{E}$ sector is difficult to establish, because of a large 'coast effect' and poor station control, but would appear to be small.

(2) Smaller $Z$ phase anomalies in the same region appear to be such that $Z$ phase-lag angles tend to values slightly less than the phase of their corresponding $Y^{\prime \prime}$ horizontal component in a roughly WNW tending direction.

(3) Some small amplitude anomaly of a $Y^{\prime \prime}$ component may also be present in the same region.

\section{Origin of the Victorian Anomaly}

The consistency of the $Z$ anomaly observed for appropriate NW-SE linear polarizations, for all events with differing spatial structure, again suggests that this feature is not the local effect of 'globally' induced currents. Indeed, the possibility of any significant current flow through the Otway Basin sediments appears unlikely, since:

(1) Such a current path would probably be shorted out by the much higher conductance per unit width of the Bass Strait waters (the absence of large $Z$ response at TYB and TGN (Fig. 2) seems in any case to indicate no great current flow in the Bass Strait).

(2) The east-west orientation of the Otway Basin isopachs (Fig. 9) and thus the orientation of any resistive current flow, cannot be reconciled with the observed orientation and symmetry of the observed anomalous $Z$.

(3) Such an explanation does not explain the sensitivity of $Z$ response to polarization of the horizontal field.

It is concluded that the Victorian Anomaly is the direct expression of anomalous induction due to a local conductivity structure. The consistent anomaly observed, for all horizontal field variations polarized in the north-west sector, and the tendency of $Z$ phase to approach that of the horizontal variation in the SE-NW sense (or alternatively, the tendency of the real Parkinson vectors to be deflected eastwards), suggests that an anomalously conductive zone lies in the region to the south-east of DNM. This zone probably has a lateral conductivity boundary near DNM, which is elongated along a NE axis, to produce the observed polarization dependence of the anomaly; the zone should be quite narrow along a NW axis, to give little anomaly for NE polarized field, and also to ensure little anomalous $Z$ response at station TYB. The orientation of the sediment isopachs (Fig. 9) appears to rule out local induction in the Otway Basin as a cause.

\section{Computer modelling}

Two-dimensional modelling, as performed for the East Coast Anomaly, has very limited application to the Victorian Anomaly. Modelling criteria similar to those of Section 2 can be obtained, and Fig. 10 shows estimates of a normalized $Z^{A}$ amplitude parameter plotted against frequency. This $Z^{\mathrm{A}}$ parameter is defined as $\left(Z_{\mathrm{DNM}}-Z_{\mathrm{TYB}}\right) / Y_{\mathrm{GBR}}^{\prime \prime}$ where $Y^{\prime \prime}$ is the horizontal component along profile line $V$, marked in Fig. 1; and $Z^{A}$ is formed from contour maps of near-linear polarizations in the north-west sector. $Z_{\mathrm{TYB}}$ and $Y_{\mathrm{GBR}}^{\prime \prime}$ are chosen as representing near-normal regional values, and $Z^{\mathrm{A}}$ gives a measure of the maximum observed anomalous effect of the Victorian Anomaly. The value obtained from the micropulsation event is somewhat doubtful, since both Victorian Anomaly and South-West Coast Anomaly appear on the $Z$ maps for this near-circular horizontal polarization (Lilley \& Bennett 1973a). 


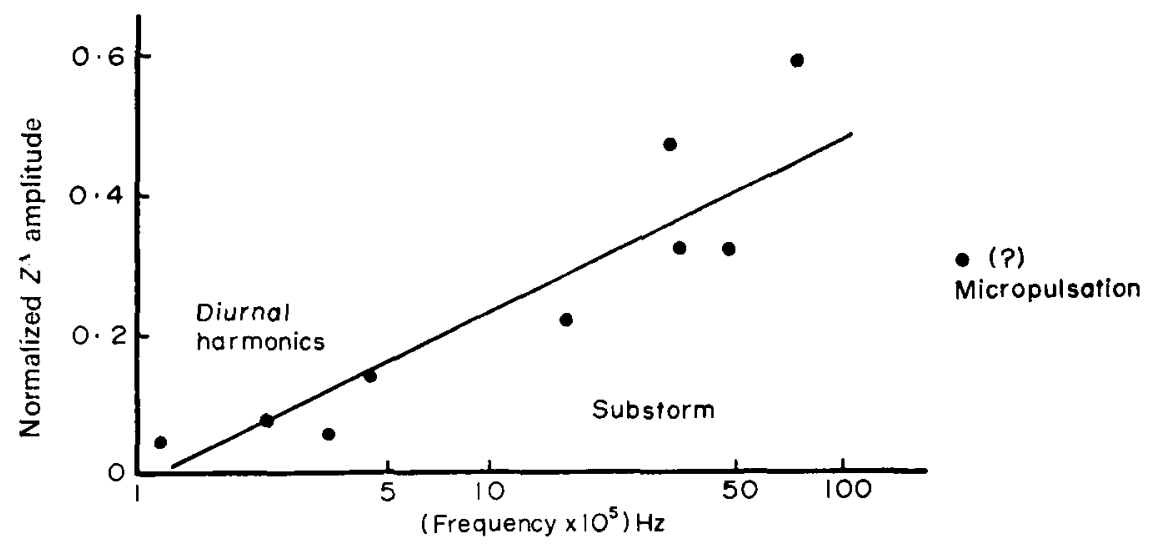

FIG. 10. Values of $Z^{\mathrm{A}}$ amplitude $v$. frequency response at station DNM. $Z^{\mathrm{A}}$ amplitudes normalized as per text; and selected for appropriate horizontal polarizations.

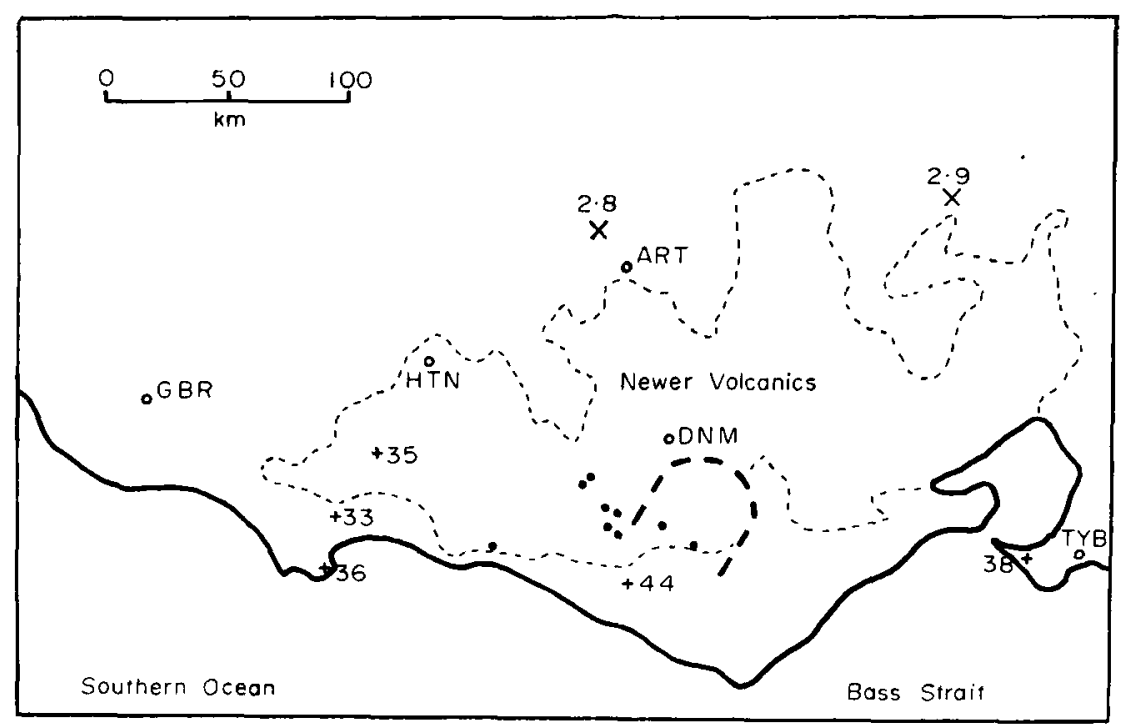

FIG. 11. Possible outline for the postulated conductive zone associated with the Victorian Anomaly. Also shown are Newer Volcanics of Victoria; basanitic eruptive centres $(\bullet)$ after Irving (1971); heat flows $(x)\left(\mathrm{cal} / \mathrm{cm}^{2} \mathrm{sec}\right)$ after Jaeger (1970); and thermal gradients $(+)\left({ }^{\circ} \mathrm{C} / \mathrm{km}\right)$ after Sass (private communication).

A second parameter is obtained from changes in the horizontal component $Y^{\prime \prime}$ along profile line $V$ of Fig. 1, roughly perpendicular to the strike axis of the magnetic variation anomaly. The $Y^{\prime \prime}$ amplitude at the most "anomalous' station DNM is observed to be no more than 15 per cent greater than that at the 'normal' station GBR. Just as for the East Coast Anomaly, no useful parameter can be obtained from the $Z$ phase structure.

The main body of the postulated conductive zone cannot extend far north of DNM; and furthermore, the zone may have appreciable mutual inductance with such features as the laterally discontinuous ocean waters and the Otway Basin sediments. Thus representation of the observed variation anomaly by the electromagnetic response of a two-dimensional conductivity configuration is undoubtedly a severe approximation. The limited station coverage further complicates interpretation. 
Modelling of the $Z^{\mathrm{A}}$ and $Y^{\prime \prime}$ amplitude parameters, using the $E$-polarization program of Jones and Pascoe was attempted in a very restricted manner. It was concluded that satisfaction of the $Z^{\mathrm{A}}$ and $Y^{\prime \prime}$ parameters may be approached by some zone with conductivity of order $1(\mathrm{ohm}-\mathrm{m})^{-1}$, at a depth possibly much less than $50 \mathrm{~km}$, and situated within a few tens of kilometres of DNM. Having regard for these conclusions, and for the polarization sensitivity and symmetry of the observed anomaly, a possible outline for the zone is shown in Fig. 11 relative to the outcrop of the Victorian Newer Volcanics. Further observations are needed to verify the existence, position, extent and depth of such a conductive zone.

It was also concluded from two-dimensional modelling that any reasonable values of conductivity in the sediments of the Otway Basin could not produce the appreciable anomalous $Z$ observed at the very long period diurnal harmonics.

\section{Geological interpretation}

The conductive zone is assumed to be associated with the Newer Volcanics of Victoria. These are composed of a mixed tholeiitic-alkaline basaltic suite covering an extensive region of south-west Victoria. Irving (1971) noted that a very broad sequence of activity may be represented, from generally tholeiitic flood plains, through superposed hawaiite volcanoes, to basanitic volcanoes and maare. Wellman (1971) estimated a total of $1300 \mathrm{~km}^{3}$ of basaltic extrusion. McDougall, Allsop \& Chamalaun (1966), and Wellman, have obtained K-Ar dates on the volcanics ranging from 4.5 My to 0.57 My BP. Dating of tuffs by the $\mathrm{C}^{14}$ method gives ages of 5000-6000 years at Tower Hill (Gill 1967), a basanitic eruptive centre some $30 \mathrm{~km}$ south-west of the position of the zone suggested in Fig. 11. Thus the postulated conductive zone is considered to represent a crustal or upper mantle zone of elevated temperature and partial melt, associated with the Newer Volcanics. Consistent with this hypothesis is the fact that the zone shown in Fig. 11 appears roughly coincident with the region of the very recent known basanitic eruptive centres, also marked (after Irving) in Fig. 11. Ollier (1967) shows all the geomorphologically very young volcanic maare, some of which have been identified as basanatic, to lie in the same province.

High heat flow values in this region also suggest a crust or upper mantle of elevated temperature. Values of 2.8 and 2.9 h.f.u. have been recorded at Stawell and Castlemaine to the north of the Newer Volcanics (Jaeger 1970). Several values of thermal gradient from the south of the Newer Volcanics region are also shown (J. H. Sass, private communication). Should the thermal conductivity of the Otway Basin sediments be reasonably consistent over this region, these thermal gradients might suggest the heat flow near the postulated conductive zone to be some 25 per cent greater than at other localities nearby (for example, south of HTN).

In conclusion, it appears reasonable that the Victorian Anomaly is due to a subterranean conductive zone linked to the Newer Volcanics. A more detailed mapping of this variation anomaly should provide meaningful evidence on the tectonic history of this region.

\section{Acknowledgments}

Dr J. H. Sass is thanked for allowing us to present some of his heat flow measurements prior to their publication. A referee made many helpful suggestions. One of the authors (D.J.B.) was the recipient of a research scholarship awarded by the Australian National University.

\footnotetext{
Department of Geophysics and Geochemistry

(now the Research School of Earth Sciences), Australian National University, Canberra, A.C.T.
} 


\section{References}

Banks, R. J., 1969. Geomagnetic variations and the electrical conductivity of the upper mantle, Geophys. J. R. astr. Soc., 17, 457-487.

Bennett, D. J., 1972. Geomagnetic depth sounding studies in south-eastern Australia, Ph.D. Thesis, Australian National University.

Bennett, D. J. \& Lilley, F. E. M., 1971. The effect of the south-east coast of Australia on transient geomagnetic variations, Earth Planet. Sci. Letts, 12, 392-398.

Bennett, D. J. \& Lilley, F. E. M., 1972. Horizontal polarization in array studies of anomalous geomagnetic variations, Nature, 237, 8-9.

Bennett, D. J. \& Lilley, F. E. M., 1973. An array study of daily magnetic variations in south-east Australia, J. Geomagn. Geoelectr., 25, 39-62.

Brune, J. N., 1969. Surface waves and crustal structure: The Earth's crust and upper mantle, ed. P. J. Hart, A.G.U. Geophysical Monograph, 13, 230-242.

Bullard, E. C. \& Parker, R. L., 1970. Electromagnetic induction in the oceans; The Sea, Vol. 4, pt. 1, chap. 18, 695-730, ed. A. E. Maxwell, J. Wiley and Sons.

Cox, C. S., Filloux, J. H. \& Larsen, J. C., 1970. Electro-magnetic studies of ocean currents and electrical conductivity below the ocean floor; The Sea, Vol. 4, pt. 1, chap. 17, 637-693, ed. A. E. Maxwell, J. Wiley and Sons.

Cox, C. S., 1971. The electrical conductivity of the oceanic lithosphere; The structure and physical properties of the Earth's crust, ed. J. G. Heacock, A.G.U. Geophysical Monograph, 14, 227-234.

Duba, A., 1972. Electrical conductivity of olivine, J. geophys. Res., 77, 2483-2495.

Duba, A., Ito, J. \& Jamieson, J. C., 1973. The effect of ferric iron on the electrical conductivity of olivine, Earth Planet. Sci. Lett., 18, 279-284.

Duba, A. \& Lilley, F. E. M., 1972. Effect of an ocean ridge model on geomagnetic variations, J. geophys. Res., 77, 7100-7105.

Duba, A. \& Nicholls, I. A., 1973. The influence of oxidation state on the electrical conductivity of olivine, Earth Planet. Sci. Lett., 18, 59-64.

Everett, J. E. \& Hyndman, R. D., 1967. Geomagnetic variations and electrical conductivity structure in south-western Australia, Phys. Earth Planet. Int., 1, 24-34.

Gill, E. D., 1967. Evolution of the Warrnambool-Port Fairy coast and the Tower Hill eruption, Western Victoria; Landform studies from Australia and New Guinea, 340-364, eds J. N. Jennings \& J. A. Mabbutt, ANU Press, Canberra.

Gough, D. I. \& Camfield, P. A., 1974. Conductive structures under the Northern Rocky Mountains. J. geophys. Res., in press.

Grim, P. J., 1969. Heat flow measurements in the Tasman Sea, J. geophys. Res., 74, 3933-3937.

Hayes, D. E. \& Ringis, J., 1972. The early opening of the central Tasman Sea, Abstract, Int. Symposium Oceanogr. South Pacific, Wellington, N.Z.

Hyndman, R. D. \& Cochrane, N. A., 1972. Electrical conductivity structure by geomagnetic induction at the continental margin of Atlantic Canada, Geophys. J. R. astr. Soc., 25, 425-446.

Hyndman, R. D., Jaeger, J. C. \& Sass, J. H., 1969. Heat flow measurements on the south-east coast of Australia, Earth Planet. Sci. Letts, 8, 285-290.

Irving, A. J., 1971. Geochemical and high pressure experimental studies of xenoliths, megacrysts and basalts from south-eastern Australia, Ph.D. Thesis, Australian National University.

Jaeger, J. C., 1970. Heat flow and radioactivity in Australia, Earth Planet. Sci. Letts, 8, 285-292. 
Jones, F. W. \& Pascoe, L. J., 1971. A general computer program to determine the pertubation of alternating electric currents in a two-dimensional model of a region of uniform conductivity with an embedded inhomogeneity, Geophys. $J$. R. astr. Soc., 24, 3-30.

Jones, F. W. \& Price, A. T., 1970. The perturbations of alternating geomagnetic fields by conductivity anomalies, Geophys. J. R. astr. Soc., 20, 317-334.

Kanamori, H. \& Press, F., 1970. How thick is the lithosphere?, Nature, 226, 330-331.

Lilley, F. E. M. \& Bennett, D. J., 1972. An array experiment with magnetic variometers near the coasts of south-east Australia, Geophys. J. R. astr. Soc., 29, 49-64.

Lilley, F. E. M. \& Bennett, D. J., 1973a. Micropulsations recorded by an array of magnetic variometers, J. geophys. Res., 78, 1603-1607.

Lilley, F. E. M. \& Bennett, D. J., 1973b. Linear relationships in geomagnetic variation studies, Phys. Earth Planet. Int., 7, 9-14.

McDougall, I., Allsop, H. L. \& Chamalaun, F. H. 1966. Isotopic dating of the Newer Volcanics of Victoria, Australia, and geomagnetic polarity epochs, J. geophys. Res., 71, 6107-6118.

Molnar, P. \& Oliver, J., 1969. Lateral variations of attenuation in the upper mantle and discontinuities in the lithosphere, J. geophys. Res., 74, 2648-2682.

Ollier, C. E., 1967. Landforms of the Newer Volcanic Province of Victoria; Landform studies from Australia and New Guinea, 315-339, eds J. N. Jennings \& J. A. Mabbutt, ANU Press, Canberra.

Parker, R. L., 1970. The inverse problem of electrical conductivity in the mantle, Geophys. J. R. astr. Soc., 22, 121-138.

Parkinson, W. D., 1959. Directions of rapid geomagnetic fluctuations, Geophys. J. R. astr. Soc., 2, 1-14.

Pascoe, L. J. \& Jones, F. W., 1972. Boundary conditions and calculation of surface values for the general two-dimensional electromagnetic induction problem, Geophys. J. R. astr. Soc., 27, 179-193.

Presnall, D. C., Simmons, C. L. \& Porath, H., 1972. Changes in electrical conductivity of a synthetic basalt during melting, $J$. geophys. Res., 77, 5665-5672.

Ringis, J., 1970. Magnetic lineations in the Tasman (abstract), Geoexploration, 8, 250.

Schmucker, U., 1970. Anomalies of geomagnetic variations in the south-western United States, Bull. Scripps Inst. Oceanogr., 13, Univ. Calif.

Sclater, J. G. \& Francheteau, J., 1970. The implications of terrestrial heat flow observations on current tectonic and geochemical models of the crust and upper mantle of the Earth, Geophys. J. R. astr. Soc., 20, 509-542.

Sclater, J. G., 1972. New perspectives in terrestrial heat flow, Tectonophysics, 13, 257-291.

Tammemagi, H. Y. \& Lilley, F. E. M., 1971. Magnetotelluric studies across the Tasman geosyncline, Australia, Geophys. J. R. astr. Soc., 22, 505-516.

Vogt, P. R. \& Conolly, J. R., 1971. Tasmantid guyots, the age of the Tasman Basin, and motion between the Australia plate and the mantle, Bull. geol. Soc. Am., 82, 2577-2583.

Wellman, P., 1971. The age and paleomagnetism of the Australian Cenozoic rocks, Ph.D. Thesis, Australian National University. 